\title{
A Corrosion Initiation Prediction Model for Reinforced Concrete Structures in Coastal Areas of the Arabian Gulf
}

\author{
Mohamed R. Sakr ${ }^{1 *}$,Osama El-Mahdy ${ }^{2}$, Karim El-Dash ${ }^{3}$ \\ ${ }^{1}$ Assistant Lecturer (Department of Civil Engineering, Faculty of Engineering at Shoubra, Benha \\ University, Cairo, Egypt) \\ ${ }^{2}$ Professor (Department of Civil Engineering, Faculty of Engineering at Shoubra, Benha University, \\ Cairo, Egypt) \\ ${ }^{3}$ Professor (Department of Civil Engineering, Faculty of Engineering at Shoubra, Benha University, \\ Cairo, Egypt)
}

\begin{abstract}
Chloride-induced corrosion is the main threat for structures located in the Arabian Gulf coastal areas. So, it is important predict its initiation time to evaluate the performance of structures.In this paper, a prediction model is proposed for this purpose to be applied in the Arabian Gulf coastal areas. The model is solved numerically by the Finite Element Method, and verified by application on an existing building in the United Arab Emirates. The proposed modelis found to be well predict the chloride penetration in concrete and can be used for the durability design of new structures or the assessment of existing structures. Also, it is found that assuming the surface chloride concentration at interior elements in the structures to be half of that at the exterior elements is a good approximation when predicting its initiation time.
\end{abstract}

Keywords: Arabian Gulf, Chloride Diffusion, Concrete, corrosion, FEM and Service Life.

\section{Introduction}

The coastal areas in the Arabian Gulf region are mainly characterized by its harsh environmentwith high temperature accompanied by high relative humidity. The monthly mean air temperature varies from $20^{\circ} \mathrm{C}$ to $35^{\circ} \mathrm{C}$ with a daily temperature reaching sometimes $50^{\circ} \mathrm{C}$ in summer, the relative humidity varies from $30 \%$ to $90 \%$ during the year [1]. Under these conditions, reinforced concrete structures, which constitutes a wide sector of the construction industry, deteriorates very rapidly, and fail before the intended service life. In coastal areas, corrosion induced by chloride ingress into concrete is considered to be the main deterioration mechanism [2].

Corrosion can eventually cause cracking and spalling of concrete cover along the bar the length due to volume expansion of rust, and developed tensile stresses at the reinforcement/concrete interface [3]. The repair of corrosion damage costs a fortune for example, the estimated cost of corrosion in 2011 is US\$14.26 billion in the United Arab Emirates (UAE), US\$24.84 billion in Kingdom of Saudi Arabia (KSA), and US\$ 7.78 billion in State of Qatar [4]. Hence, more attention was given in the last decades to develop effective corrosion control strategies regarding performance and cost. These strategies can be evaluated by developing models to predict the corrosion initiation time. Several models were developed to predict its initiation time starting in 1972 when Collepardi et al. [5] applied Fick's law on chloride diffusion in concrete. Then, several analytical, empirical and numerical modelswere developed along the time [6-8].

In this paper, a corrosion initiation prediction model is proposed to be applied in the coastal areas of the Arab Gulf region. The proposed modelcan be simply applied by the practice engineer. The model is solved numerically be the Finite Element Method then validatedthrough the application on an existing building in UAE located directly on the Arabian Peninsula.

\section{Proposed model For Chloride Ingress In Concrete}

Although chloride ions may transport through concrete by different mechanisms, diffusion due to concentration gradient is considered to be the dominant mechanism [9]. Therefore, the model is based as most others on Fick's second law of diffusion which can be written in the form of the following partial differential equation for one-dimensional diffusion problem [10]:

$$
\frac{\partial C(x, t)}{\partial t}=D \frac{\partial^{2} C(x, t)}{\partial x^{2}}
$$

where $C(x, t)$ is the chloride concentration at distance $x$ from the chloride-exposed surface at time $t$, and $D$ is the chloride diffusion coefficient of concrete.To account for two-dimensional diffusion, Eq. (1) can be expandedto:

$$
\frac{\partial C(x, y, t)}{\partial t}=D\left[\frac{\partial^{2} C(x, y, t)}{\partial x^{2}}+\frac{\partial^{2} C(x, y, t)}{\partial y^{2}}\right]
$$


where $C(x, y, t)$ is the chloride concentration at point $(x, y)$ in the element domain at time $t$. Noting that in order to solve Fick's law, a boundary condition (chloride concentration at surface), and initial condition (chloride content of the concrete mix) are required.

\subsection{Expression for Diffusion Coefficient (D)}

It is obvious from Eq. (1) and Eq. (2) that $D$ is the key element that control the penetration of chloride ions into concrete. In this model, three main points are considered regarding the diffusion coefficient: i)It is not constant but decreases with time as the hydration process proceeds due to the refinement of pore structure [11], ii) Increasing temperature results in increasing the diffusion coefficient without changing the trend of chloride profiles [12], iii) Relative humidity significantly influences the diffusion coefficient and considered along with the temperature, the main environmental variables that affect the chloride ingress into concrete [13,14]. So, the next equation will be adopted for diffusion coefficient to consider the previously mentioned points:

$$
D=D_{\text {ref }} * F(t) * F(T) * F(R H)
$$

where $D_{r e f}$ is the reference diffusion coefficient at reference time $t_{r e f}, F(t), F(T)$, and $F(R H)$ are factors multiplied $D_{\text {ref }}$ by to account for the age effect, temperature, and relative humidity respectively. Thomas and Bentz [15] proposes $D_{\text {ref }}$ based on a large database of bulk diffusion tests to be:

$$
D_{\text {ref }}=10^{(-12.06+2.40 * w / c)}\left(\mathrm{m}^{2} / \mathrm{s}\right)
$$

where $\mathrm{w} / \mathrm{c}$ is the water to cement ratio.

The age factor $F(t)$ represents the reduction of $\mathrm{D}$ with time, and is generally accepted to be expressed as [15-17]:

$$
F(t)=\left(\frac{t_{r e f}}{t}\right)^{m}
$$

where $t_{\text {ref }}$ is the reference age (usually 28 days), $t$ is the age of exposure and $m$ is an age factor to account for the refinement of pore structure, and is proposed to be [15]:

$$
m=0.2+0.4(\% F A / 50+\% S G / 70) \leq 0.6
$$

where $\% F A$ and $\% S G$ are the amount of fly ash $(\leq 50 \%)$ and slag $(\leq 70 \%)$, respectively. The equation for age factor $m$ considers only the addition of fly ash and slag. Silica fume is assumed to have no effect on the age factor, but affects the reference diffusion by a multiplied factorexp $(-0.165 * \% S F)$, where $\% S F$ is the amount of silica fume. Value of $F(t)$ continues to decrease until the hydration process is complete and no further pore refinement takes place, assumed 25 years. Beyond this point its value remains constant at the 25 years value [15].

The factor $F(T)$ represent the effect of temperature and isobtained from Arrhenius law as [12]:

$$
F(T)=\exp \left[\frac{U_{c}}{R}\left(\frac{1}{T_{\text {ref }}}-\frac{1}{T}\right)\right]
$$

where $U_{c}$ is the activation energy of chloride diffusion in concrete, reported as $23,39.9 \mathrm{~kJ} / \mathrm{mol}$ for water to cement ratio 0.35 and 0.6 , respectively [12], assumed to be $35 \mathrm{~kJ} / \mathrm{mol}$ in this study, $R$ is the gas constant $(8.314$ $\mathrm{J} / \mathrm{mol} \mathrm{K}), T_{r e f}$ is the reference temperature $(293.15 \mathrm{~K})$, and $T$ is the ambient temperature.

The effect of relative humidity was taken into account by multiplying the reference diffusion coefficient by a factor $F(R H)[13]$ :

$$
\mathrm{F}(\mathrm{RH})=\left[1+\frac{(1-\mathrm{RH})^{4}}{(1-\mathrm{RHc})^{4}}\right]^{-1}
$$

Where $\mathrm{RH}$ is the ambient relative humidity, and $\mathrm{RH}_{c}$ is the reference relative humidity (assumed 75\% [18])

\subsection{Expression forSurface Chloride Concentration $\left(C_{s}\right)$}

Surface chloride concentration $C_{s}$ represents the severity of the surrounding environment to the building, and the boundary condition of the diffusion problem. Adopting appropriate values for $C_{s}$ is important to predict adequately the future chloride penetration [19].It is found that $C_{s}$ builds up at concrete surface and increases with time [20-22]. Ann et al. [23] proposed a realistic relation for surface chloride build-up $\left(C s=C_{0}+\right.$ $k \sqrt{t}$; where $C_{0}$ is the initial build-up of surface chloride at initial exposure, $k$ is a constant under a linear buildup condition).In this model, this proposed relation is adopted, but the constant $k$ is used as a constant under a square root build-up condition.

\section{Application Of The Proposed Model: A Case Study}

To evaluate the proposed model as a basis for an improved condition assessment of concrete structures, realistic data was needed. For this reason, a reinforced concrete building was assessed to collect the necessary data. In this section, the durability investigations of the structure is presented with the description the results obtained. 


\subsection{Description of the Building}

The hotel building was built in the early eighties, located in UAE directly on the shore of the Arabian Gulf. The hotel is exposed to highly hot, humid, and salty weather conditions. Alayout for the building is shown in Fig. 1. It consists of four parts; a 6 story concrete-framed main building, two reinforced concrete wings which extend towards the sea, and two lines of single story buildings built along the plot boundaries. The wings are a series of staggered units set on a skewed axis consisting of ground and first floors. It is worth mentioning that the buildings are being regularly repaired (last repair in 2009), and in the time of the assessment, the two boundary units are being repaired. So, the study is limited to only the first three parts. The mix design of the concrete used in the building applied $350 \mathrm{~kg} / \mathrm{m}^{3}$ of cement. The water-to-cement ratio and mix density are 0.40 and $2320 \mathrm{~kg} / \mathrm{m}^{3}$, respectively.

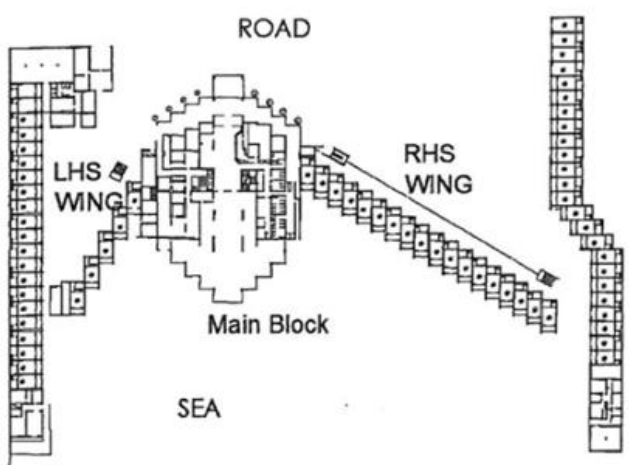

Fig. 1: Layout of the Hotel.

\subsection{Visual Inspection of the Building}

In order to assess the condition of the structure, visual inspection is performed to identify the areas of defect, and to select the most significant representative structural elements of the building to conduct the required tests. The three parts of the building are inspected namely the main part, left hand side(LHS) wing, and right hand side (RHS) wing. Fig. 2 shows the building and the severe environment to which it is exposed.

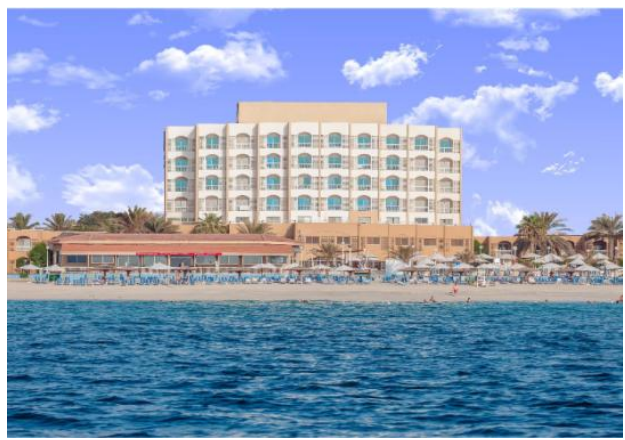

Fig. 2: A Photograph of the Hotel Building Investigated Suffering Severe Weather.

\subsubsection{Visual Assessment of the Main Part}

At the road side, vertical cracks were observed in some columns. Also, separation was observed in granite cladding of some columns in front of the main gate due to spalling of concrete cover. Some of the observed defects are shown in Fig. 3.
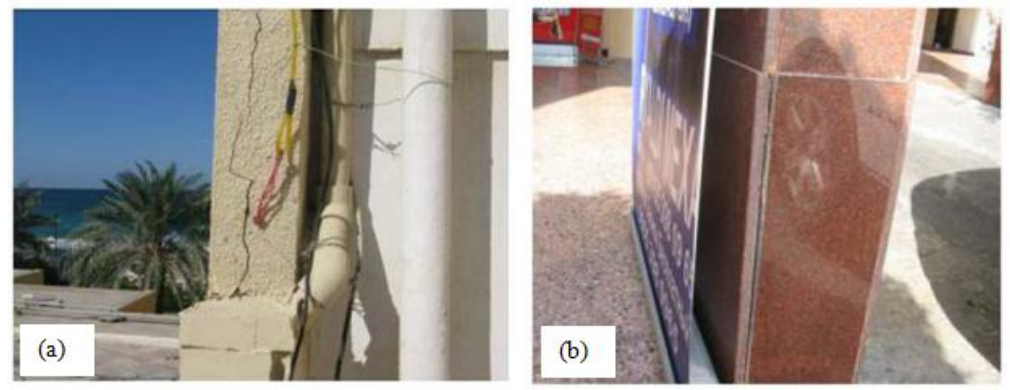

Fig. 3: A Photograph Showing (a) Column Cracks, and (b) Granite Separation 
At the sea side, horizontal cracks on the spandrel panels and vertical cracks on columns and wall were observed. Some of the observed defects are shown in Fig. 4. Also, horizontal and vertical cracks were observed at the center and top of the walls in the roof.The internal inspection showed that there are not any defects or cracks.

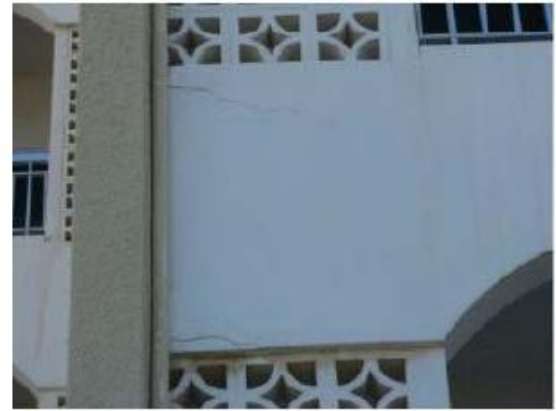

(a)

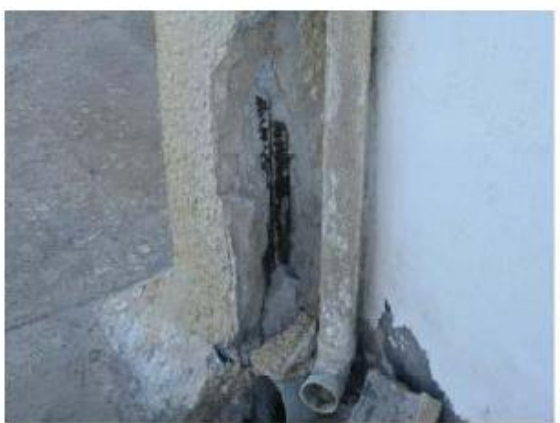

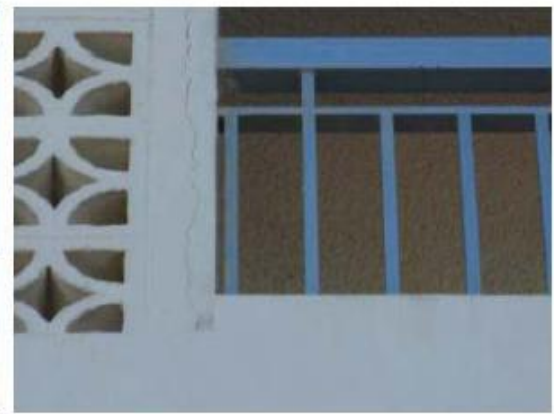

(b)

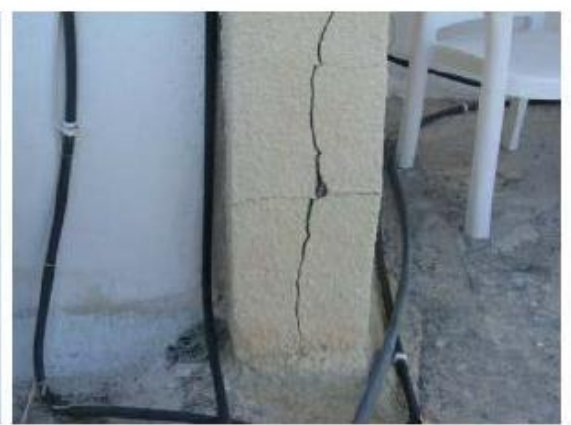

(c)

Fig. 4: A Photo Showing (a) Cracks at Façade Wall in First Floor, (b) Crack at First Floor Column, and (c) Cracks at Bottom of Column at Service Level.

\subsubsection{Visual Assessment of the LHS and RHS Wings}

In these parts, the balconies are supported by cantilever beams with horizontal beams spanning between the ends of the cantilevers. Cracks of various sizes and repetitive in nature were observed at these beams. Also, cracks were observed at the stair case unit located at the end of each wing. Horizontal and vertical cracks were observed at the columns. These defects are shown in Fig .5.
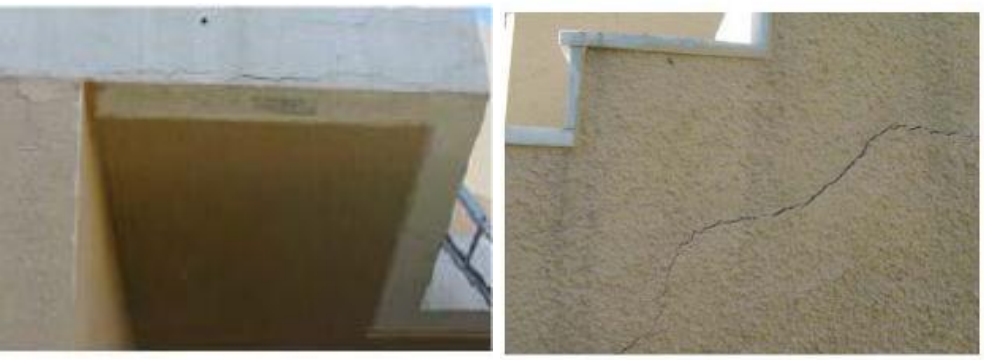

(a)
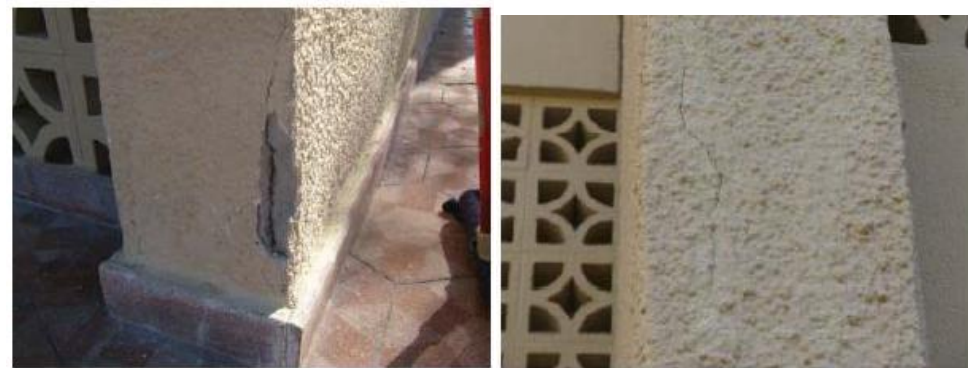

(b)

Fig. 5: A photo showing (a) cracks at beams and stair cases, and (b) cracks at columns in different locations. 


\subsection{Condition Assessment of the Building}

Based on the visual inspection results, a number of specimens were taken from different defect locations of external and internal elements. The tests included cover measurements, and chloride content of concrete. The concrete cover measurements indicated that the average values of cover to reinforcement are $15 \mathrm{~mm}$, and $30 \mathrm{~mm}$ for slabs and columns, respectively.

It is important to mention that the chloride content in concrete tests were conducted by an authorized laboratory centerin UAE. The tests were conducted according to BS 1881: part 124: 1988 [24]. The results of tests for different elements along with their locations are shown in Table 1. Noting that laboratory results were given as the average value of concentration in two distance ranges: $(0-25 \mathrm{~mm})$, and $(25-50 \mathrm{~mm})$, respectively.

Table 1: Chloride Concentration Test Results for Different Elements.

\begin{tabular}{|c|c|c|c|c|c|c|c|c|}
\hline Location & $\begin{array}{l}\text { Test } \\
\text { No. }\end{array}$ & Element & $\begin{array}{l}\text { Depth of } \\
\text { Sample } \\
(\mathrm{mm})\end{array}$ & $\begin{array}{c}\text { Chloride } \\
\text { Content (\% of } \\
\text { Dry Weight of } \\
\text { Cement) }\end{array}$ & $\begin{array}{l}\text { Test } \\
\text { No. }\end{array}$ & Element & $\begin{array}{c}\text { Depth of } \\
\text { Sample (mm) }\end{array}$ & $\begin{array}{l}\text { Chloride Content } \\
\text { (\% of Dry Weight } \\
\text { of Cement) }\end{array}$ \\
\hline \multirow{11}{*}{ 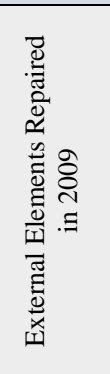 } & 1 & E-1A & $(0-25)$ & 0.86 & 12 & E-6B & $(25-50)$ & 0.86 \\
\hline & 2 & E-1B & $(25-50)$ & 0.53 & 13 & E-7A & $(0-25)$ & 0.80 \\
\hline & 3 & E-2A & $(0-25)$ & 1.06 & 14 & E-7B & $(25-50)$ & 0.66 \\
\hline & 4 & E-2B & $(25-50)$ & 1.13 & 15 & E-8A & $(0-25)$ & 0.73 \\
\hline & 5 & E-3A & $(0-25)$ & 0.99 & 16 & E-8B & $(25-50)$ & 0.66 \\
\hline & 6 & E-3B & $(25-50)$ & 1.06 & 17 & E-9A & $(0-25)$ & 0.73 \\
\hline & 7 & E-4A & $(0-25)$ & 0.99 & 18 & E-9B & $(25-50)$ & 0.66 \\
\hline & 8 & E-4B & $(25-50)$ & 1.13 & 19 & E-10A & $(0-25)$ & 0.80 \\
\hline & 9 & E-5A & $(0-25)$ & 0.80 & 20 & E-10B & $(25-50)$ & 0.73 \\
\hline & 10 & E-5B & $(25-50)$ & 0.73 & 21 & E-11A & $(0-25)$ & 0.73 \\
\hline & 11 & E-6A & $(0-25)$ & 0.99 & 22 & E-11B & $(25-50)$ & 0.66 \\
\hline \multirow{6}{*}{ 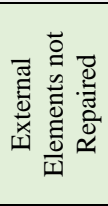 } & 23 & E-12A & $(0-25)$ & 1.92 & 29 & E-15A & $(0-25)$ & 2.39 \\
\hline & 24 & E-12B & $(25-50)$ & 1.92 & 30 & E-15B & $(25-50)$ & 2.52 \\
\hline & 25 & E-13A & $(0-25)$ & 1.99 & 31 & E-16A & $(0-25)$ & 2.32 \\
\hline & 26 & E-13B & $(25-50)$ & 2.05 & 32 & E-16B & $(25-50)$ & 2.39 \\
\hline & 27 & E-14A & $(0-25)$ & 1.92 & 33 & E-17A & $(0-25)$ & 2.39 \\
\hline & 28 & E-14B & $(25-50)$ & 1.99 & 34 & E-17B & $(25-50)$ & 2.52 \\
\hline \multirow{12}{*}{ 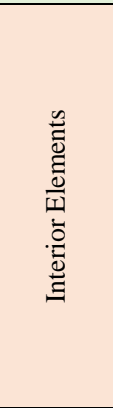 } & 35 & E-18A & $(0-25)$ & 0.66 & 47 & E-24A & $(0-25)$ & 0.40 \\
\hline & 36 & E-18B & $(25-50)$ & 0.66 & 48 & E-24B & $(25-50)$ & 0.33 \\
\hline & 37 & E-19A & $(0-25)$ & 0.33 & 49 & E-25A & $(0-25)$ & 0.33 \\
\hline & 38 & E-19B & $(25-50)$ & 0.40 & 50 & E-25B & $(25-50)$ & 0.27 \\
\hline & 39 & E-20A & $(0-25)$ & 0.53 & 51 & E-26A & $(0-25)$ & 0.4 \\
\hline & 40 & E-20B & $(25-50)$ & 0.53 & 52 & E-26B & $(25-50)$ & 0.33 \\
\hline & 41 & E-21A & $(0-25)$ & 0.53 & 53 & E-27A & $(0-25)$ & 0.46 \\
\hline & 42 & E-21B & $(25-50)$ & 0.46 & 54 & E-27B & $(25-50)$ & 0.53 \\
\hline & 43 & E-22A & $(0-25)$ & 0.46 & 55 & E-28A & $(0-25)$ & 0.53 \\
\hline & 44 & E-22B & $(25-50)$ & 0.46 & 56 & E-28B & $(25-50)$ & 0.60 \\
\hline & 45 & E-23A & $(0-25)$ & 0.53 & 57 & E-29A & $(0-25)$ & 0.33 \\
\hline & 46 & E-23B & $(25-50)$ & 0.53 & 58 & E-29B & $(25-50)$ & 0.27 \\
\hline
\end{tabular}

Comparing the values of chloride concentration with the threshold value, that is the chloride concentration required at steel surface for corrosion to initiate, assumed to be $0.20 \%$ by weight of cement [25], it is found that all the values exceeds the threshold value indicating that corrosion has been initiated in all the investigated members and repair is mandatory in certain locations. So, in order to check the proposed model, the predicted values of chloride concentrations from the model are compared with those obtained from the experimental testing. However, the last repair in 2009 was performed by removing and replacing the external concrete cover. So, the accumulated chloride in the concrete core with time still as it is, and the predicted values from the model in the distance range of 25 to $50 \mathrm{~mm}$ cannot be compared with the experimental results. Thus, the comparison is limited only to the range of 0 to $25 \mathrm{~mm}$ from the surface. Also, no previous data exists regarding the repair of elements 12 to 17 , so it is assumed that age of these elements is 33 years.

\subsection{Defining Model Parameters}

Once the data from the investigated structure has been collected, the proposed model consistency will be checked. The data required as input parameters for the model are presented in the following subsections.

\subsubsection{Chloride Diffusion Coefficient $(D)$}

The chloride diffusion coefficient is calculated from Eq. (3). Based on the value of water to cement ratio $(0.40)$, the reference diffusion coefficient $\left(D_{28}\right)$ is $10^{(-12.06+2.40 * 0.40)}$ that is $7.94 \mathrm{E}-12 \mathrm{~m}^{2} / \mathrm{s}$. No mineral admixtures are used, thus the age factor is 0.20 . The temperature and relative humidity change over the year at 
the location of the building are shown in Fig. 6 [26].In the model, the average annual temperature, and relative humidity are used which are $33.5^{\circ} \mathrm{C}(306.65 \mathrm{~K})$, and $67 \%$ respectively.
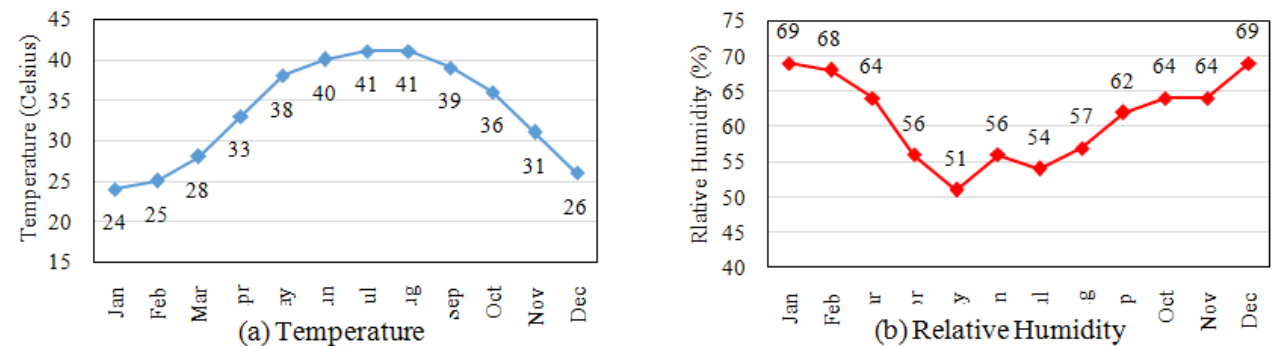

Fig. 6: Variation of Temperature and Relative Humidity during the Year at the Location of Building.

\subsubsection{Surface Chloride Concentration $\left(C_{s}\right)$}

No data were available on $C_{s}$ at the location of the building so it is assumed based on the data given by Costa [20] for atmospheric exposure(elements exposed to air-borne chlorides carried by the sea wind). The data used were given for concrete of $w / c$ ratio 0.5 , cement content of $300 \mathrm{~kg} / \mathrm{m}^{3}$, and dry density of $2330 \mathrm{~kg} / \mathrm{m}^{3}$. The values for $C_{s}$ were given as \% of weight of concrete. Using the mix design in formation these values are transformed to be as $\%$ of weight of cement as shown in Table 2.

Table 2: Values of $C_{s}$ at Different Times for the Atmospheric Exposure [20].

\begin{tabular}{|c|c|c|c|c|c|c|c|c|}
\hline Time (years) & 1 & 1.25 & 1.5 & 2 & 2.5 & 3 & 3.5 & 4 \\
\hline$C_{s}(\%$ wt of concrete $)$ & 0.11 & 0.12 & 0.18 & 0.17 & 0.18 & 0.23 & 0.21 & 0.25 \\
\hline$C_{s}(\%$ wt of cement $)$ & 0.85 & 0.93 & 1.39 & 1.32 & 1.39 & 1.78 & 1.63 & 1.94 \\
\hline
\end{tabular}

These values start at one year. To represent well the surface chloride, linear regression is performed on these data to get a value for Cs at initial exposure. The obtained value of $C s$ at initial time is $0.6537 \%$ of wt of cement.This value along with the experimental results are used to perform another regression to relate $C s a n d \sqrt{t}$. Cs is found to be $0.454+0.656 \sqrt{t}$ (\% of wt of cement)

\subsection{Chloride Ion Concentration Prediction}

The initial chloride concentration is assumed to be zero. Also, the diffusion process is assumed as one dimensional problem for slabs, walls and columns because in most cases only one face of the column is externally exposed. The prediction is performed for external elements, and for interior elements assuming a lower value of $C_{s}$ than that of the external exposure. The model is solved using the Finite Element Method by COMSOL MULTIPHYSICS [27].In the case of external elements (1-11) and using the parameters defined earlier, the predicted chloride concentration variation with the distance from the surface at 4 years (the time from the last repair) is shown in Fig. 7.

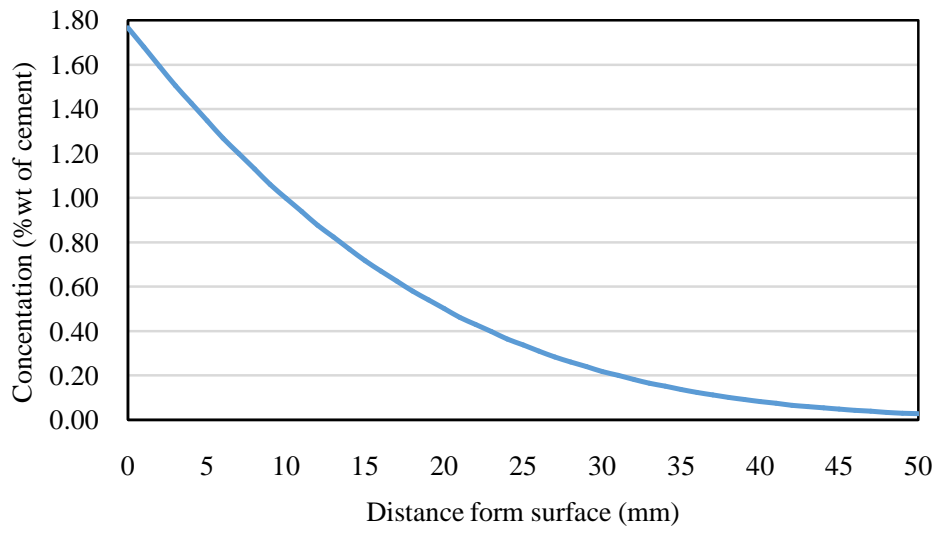

Fig. 7: Chloride Concentration Variation with the Distance from the Surface at 4 years.

The average value of the concentration from distance 0 to $25 \mathrm{~mm}$ from the surface is $0.923 \%$ of weight of cement. The percentage of difference between the predicted value and each test result is shown in Table 3 . 
A Corrosion Initiation Prediction Model for Reinforced Concrete Structures in Coastal Areas of the..

Table 3: $\%$ of Difference between the Predicted and Experimental Results for External Elements.

\begin{tabular}{|c|c|c|c|c|c|}
\hline Location & Test No. & Element & $\begin{array}{c}\text { Depth of } \\
\text { Sample }(\mathrm{mm})\end{array}$ & $\begin{array}{l}\text { Chloride Content (\% } \\
\text { of weight of cement) }\end{array}$ & $\left(\mathrm{C}_{\text {exp. }}-\mathrm{C}_{\text {pred. }}\right) / \mathrm{C}_{\text {exp }}$ \\
\hline \multirow{11}{*}{ 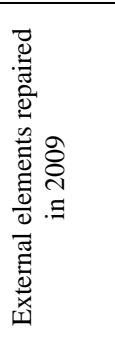 } & 1 & E-1A & $(0-25 \mathrm{~mm})$ & 0.86 & $-7.33 \%$ \\
\hline & 3 & E-2A & $(0-25 \mathrm{~mm})$ & 1.06 & $12.92 \%$ \\
\hline & 5 & E-3A & $(0-25 \mathrm{~mm})$ & 0.99 & $6.77 \%$ \\
\hline & 7 & E-4A & $(0-25 \mathrm{~mm})$ & 0.99 & $6.77 \%$ \\
\hline & 9 & E-8A & $(0-25 \mathrm{~mm})$ & 0.8 & $-15.38 \%$ \\
\hline & 11 & E-27A & $(0-25 \mathrm{~mm})$ & 0.99 & $6.77 \%$ \\
\hline & 13 & E-10A & $(0-25 \mathrm{~mm})$ & 0.8 & $-15.38 \%$ \\
\hline & 15 & E-11A & $(0-25 \mathrm{~mm})$ & 0.73 & $-26.44 \%$ \\
\hline & 17 & E-18A & $(0-25 \mathrm{~mm})$ & 0.73 & $-26.44 \%$ \\
\hline & 19 & E-19A & $(0-25 \mathrm{~mm})$ & 0.8 & $-15.38 \%$ \\
\hline & 21 & E-13A & $(0-25 \mathrm{~mm})$ & 0.73 & $-26.44 \%$ \\
\hline
\end{tabular}

The values indicate that the predicted values are of good agreement with those of the experimental results (\% difference from $6.77 \%$ to $15.38 \%$ ) except in three elements where the percentage of difference reached $26.44 \%$. The scatter of values may be due to changes in concrete characteristics, and different locations yielding some change in exposure conditions. In general, the average percentage of difference is $15.09 \%$.

For external elements with no repair history (12-17), the predicted chloride concentration variation with the distance from the surface at 33 years (the assumed age of the element) is shown in Fig. 8.

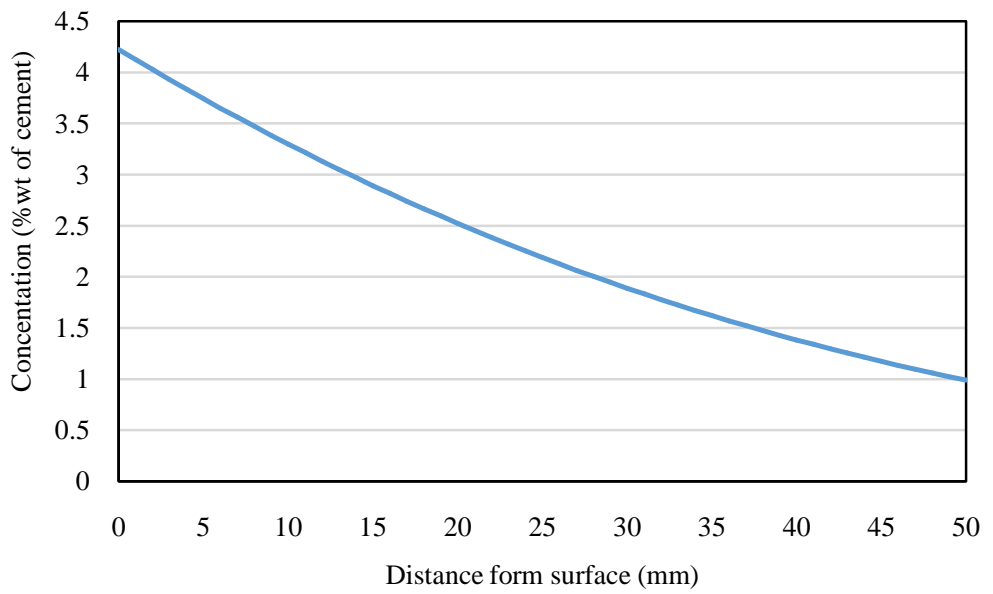

Fig. 8: Chloride Concentration Variation with the Distance from the Surface at 33 years.

The average value of the concentration from distance 0 to $25 \mathrm{~mm}$ from the surface is $3.13 \%$ of weight of cement. The percentage of difference between the predicted value and each test result is shown in Table 4 .

Table 4: \% of Difference between the Predicted and Experimental Results.

\begin{tabular}{|c|c|c|c|c|c|}
\hline Location & Test No. & Element & $\begin{array}{c}\text { Depth of } \\
\text { Sample }(\mathrm{mm})\end{array}$ & $\begin{array}{l}\text { Chloride Content (\% } \\
\text { of weight of cement) }\end{array}$ & $\left(\mathrm{C}_{\text {exp. }}-\mathrm{C}_{\text {pred. }}\right) / \mathrm{C}_{\text {exp. }}$ \\
\hline \multirow{6}{*}{ 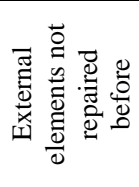 } & 23 & E-14A & $(0-25 \mathrm{~mm})$ & 1.92 & $63.02 \%$ \\
\hline & 25 & E-15A & $(0-25 \mathrm{~mm})$ & 1.99 & $57.29 \%$ \\
\hline & 27 & E-16A & $(0-25 \mathrm{~mm})$ & 1.92 & $63.02 \%$ \\
\hline & 29 & E-5A & $(0-25 \mathrm{~mm})$ & 2.39 & $30.96 \%$ \\
\hline & 31 & E-6A & $(0-25 \mathrm{~mm})$ & 2.32 & $34.91 \%$ \\
\hline & 33 & E-7A & $(0-25 \mathrm{~mm})$ & 2.39 & $30.96 \%$ \\
\hline
\end{tabular}

The values show that the predicted values vary considerably from the experimental values. This may be due tonon-availability of any data indicating whether previous repair is performed or not, and the assumed time for calculation (33 years) might beoverestimated.

In the case of internal elements and using the parameters defined in section (3.4), except for assuming the surface chloride to be half that of the external exposure i.e. $C s=0.227+0.328 \sqrt{t}$ ( $\%$ of weight of cement), the predicted chloride concentration variation with the distance from the surface at 4 years is shown in Fig. 9. 


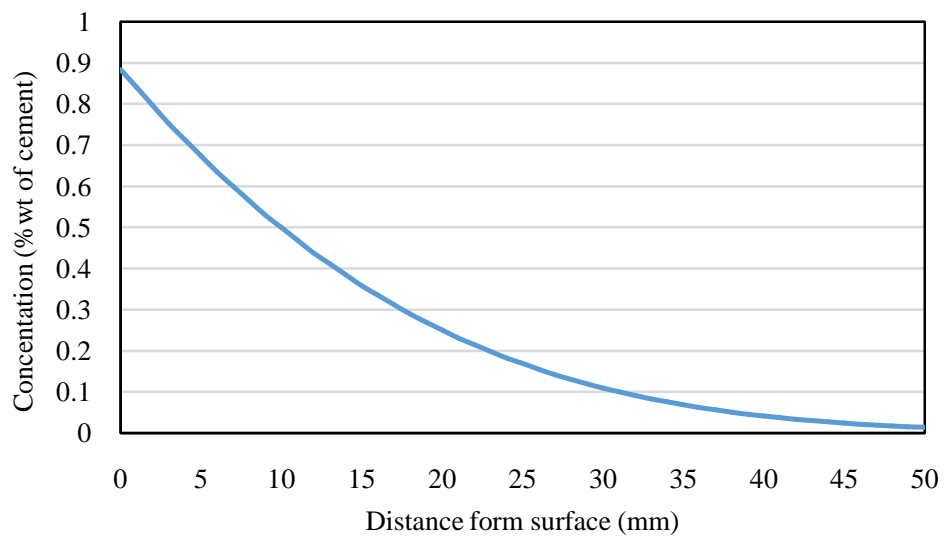

Fig. 9: Chloride Concentration Variation with the Distance from the Surface at 4 years.

The average value of the concentration from distance 0 to $25 \mathrm{~mm}$ from the surface is $0.461 \%$ of weight of cement, and the percentage of difference between the predicted value and each test result is shown in Table 5 .

Table 5: \% of Difference between the Predicted and Experimental Results for Internal Elements.

\begin{tabular}{|c|c|c|c|c|c|}
\hline Location & Test No. & Element & $\begin{array}{c}\text { Depth of Sample } \\
(\mathrm{mm})\end{array}$ & $\begin{array}{l}\text { Chloride Content (\% of } \\
\text { weight of cement) }\end{array}$ & $\left(\mathrm{C}_{\text {exp. }}-\mathrm{C}_{\text {pred. }}\right) / \mathrm{C}_{\text {exp. }}$ \\
\hline \multirow{12}{*}{ 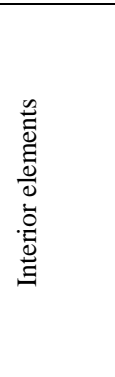 } & 35 & E-20A & $(0-25 \mathrm{~mm})$ & 0.66 & $30.15 \%$ \\
\hline & 37 & E-21A & $(0-25 \mathrm{~mm})$ & 0.33 & $-39.70 \%$ \\
\hline & 39 & E-22A & $(0-25 \mathrm{~mm})$ & 0.53 & $13.02 \%$ \\
\hline & 41 & E-23A & $(0-25 \mathrm{~mm})$ & 0.53 & $13.02 \%$ \\
\hline & 43 & E-24A & $(0-25 \mathrm{~mm})$ & 0.46 & $-0.22 \%$ \\
\hline & 45 & E-25A & $(0-25 \mathrm{~mm})$ & 0.53 & $13.02 \%$ \\
\hline & 47 & E-26A & $(0-25 \mathrm{~mm})$ & 0.4 & $-15.25 \%$ \\
\hline & 49 & E-28A & $(0-25 \mathrm{~mm})$ & 0.33 & $-39.70 \%$ \\
\hline & 51 & E-29A & $(0-25 \mathrm{~mm})$ & 0.4 & $-15.25 \%$ \\
\hline & 53 & E-9A & $(0-25 \mathrm{~mm})$ & 0.46 & $-0.22 \%$ \\
\hline & 55 & E-17A & $(0-25 \mathrm{~mm})$ & 0.53 & $13.02 \%$ \\
\hline & 57 & E-30A & $(0-25 \mathrm{~mm})$ & 0.33 & $-39.70 \%$ \\
\hline
\end{tabular}

Also, the values indicate that the predicted values are of good agreement with the experimental values (\% difference from $0.22 \%$ to $15.25 \%$ ) except in some elements where the percentage of difference reached $30.15 \%$, and $39.70 \%$. This might be due to change in concrete characteristics, exposure conditions for those elements, and the assumption for surface and initial chloride concentration. The average percentage of difference is $19.35 \%$.

\section{Conclusions}

In this paper, a model is proposed for prediction of the service life of concrete structures in the Arabian Gulf coastal areas. The model is found tobe accurate in predicting the chloride penetration in concrete and can be used in the durability design of new structures or the assessment of existing structures. Also, it is found that assuming the surface concentration at interior elements in the structures to be half of that at the exterior elements is a good approximation when predicting their service life.

\section{References}

[1] Zein-Alabideen, H.: Concrete in the hot and severe environment of the Arabian Gulf Region. 26th Conference on Our World in Concrete \& Structures (2001).

[2] Broomfield, J.:Corrosion of steel in concrete, understanding, investigating \& repair. E\&FN Spon, London, (1997).

[3] Glanville, J., Neville, A.: Prediction of Concrete Durability. E\&FN Spon, London (1997).

[4] Lim, H.: Assessing Level and Effectiveness of Corrosion Education in the UAE. International Journal of Corrosion (2012).

[5] Collepardi, M., Marcialis, A., Turriziani,R.: Penetration of chloride ions into cement pastes and concretes. J. Am. Ceram. Soc. 55(10), 534-535 (1972).

[6] Tuutti, k.: Corrosion of steel in concrete. Swedish Cement and Concrete Research Institute (CBI), Report Fo 4.82, Stockholm (1982).

[7] DuraCrete, General guidelines for durability design and redesign. The European Union- BriteEuRam III, Project no. BE951347/R15, Probabilistic Performance based Durability Design of Concrete Structures(2000).

[8] Oslakovic, IS., Bjegovic, D., Mikulic, D., Krstic, V.: Development of service life model CHLODIF ++. Computation Modeling of Concrete Structures. CRC Press (2014).

[9] Poulsen, E., Mejlbro,L.: Diffusion of Chloride in Concrete: Theory and Application. E\&FN Spon, London(2005).

[10] Crank, J.: The mathematics of diffusion. Second edition. Clarendon Press. Oxford, UK(1986).

[11] Shim, S.: Corner effect on chloride ion diffusion in rectangular concrete media. KSCE J. Civil. Eng.6, 19-24 (2002). 
[12] Yuan, Q., Shi, C., De Schutter, G., Audenaert, K.: Effect of temperature on transport of chloride ions in concrete. In M. G. Alexander et al. (Eds.), Concrete repair, rehabilitation and retrofitting II, 345-351 (2009).

[13] Saetta, A., Scotta,R., Vitaliani,R.: Analysis of chloride diffusion into partially saturated concrete. ACI Mater. J. 90(5), 441-451 (1993).

[14] Andrade, C., \& Castillo, A.: Evolution of reinforcement corrosion due to climatic variations. Mater.and Corr. 54(6), 379-386 (2003).

[15] Thomas, M., Bentz, E.: Computer program for predicting the service life and life-cycle costs of reinforced concrete exposed to chlorides. Life365 Manual(2001).

[16] Magnat, P., Molly,B.: Predicting of long term chloride concentration in concrete. Mater.Struct. 27, 338-346 (1994).

[17] Maage, M., Helland, S., Carlsen, J.: Chloride penetration in high performance concrete exposed to marine environment. Proc. of RILEM international Workshop on Durability of High Performance Concrete, 194-207 (1994).

[18] Bazant, Z., Najjar, L.: Nonlinear water diffusion in non-saturated concrete. Mater.Struct. 5(25), 3-20 (1972).

[19] Meira, G., Andrade, C., Padaratz, I., Alonso, C., Borba, J.: Chloride penetration into concrete structures in the marine atmospheric zone -relationship between deposition of chlorides on the wet candle and chlorides accumulated into concrete. Cem. Conc. Compos. 29(9), 667-676, (2007).

[20] Costa, A., Appleton,J.: Chloride penetration into concrete in marine environment - Part II: Prediction of long term chloride penetration. Mater.andStruct. 32, 354-359 (1999).

[21] Thomas, M., Bamforth, P.: Modeling chloride diffusion in concrete effect of fly ash and slag. Cem.Concr. Res. 29, 487-495 (1999).

[22] Song, H., Lee, C-H., Ann,K.: Factors influencing chloride transport in concrete structures exposed to marine environments. Cem.Concr. Compos. 30, 113-121 (2008).

[23] Ann, K., Ahn, J., Ryou, J.: The importance of chloride content at the concrete surface in assessing the time to corrosion of steel in concrete structures. Constr. Build. Mater. 23, 239-245 (2009).

[24] BS 8110. Testing concrete, Part 124. Methods for analysis of hardened concrete. United Kingdom (1988).

[25] ACI 222R-01. Protection of Metals in concrete against corrosion.

[26] http://www.worldweatheronline.com/Sharjah-weather-averages/Sharjah/AE.aspx

[27] COMSOL MULTIPHYSICS, user guide (www.comsol.com). 